\title{
Effects of Cadmium on Mineral Metabolism and Antioxidant Enzyme Activities in Salix matsudana Koidz
}

\author{
Jinhua Zou, Xiaoshuo Shang, Chonghao Li, Jie Ouyang, Binbin Li, Xiangjun Liu* \\ Tianjin Key Laboratory of Animal and Plant Resistance, College of Life Sciences, \\ Tianjin Normal University, Tianjin, China
}

Received: 25 November 2017

Accepted: 2 January 2018

\begin{abstract}
Salix matsudana Koidz was exposed to different concentrations of Cd $(0,10,50$, and $100 \mu \mathrm{mol} / \mathrm{L})$ to study the effects of $\mathrm{Cd}$ on mineral metabolism and antioxidant enzyme activities. The results showed that plant height and root length were inhibited by 50 and $100 \mu \mathrm{mol} / \mathrm{L} \mathrm{Cd}$, except the one under $10 \mu \mathrm{mol} / \mathrm{L}$ $\mathrm{Cd}$ treatment. The $\mathrm{Cd}$ content accumulated in different organs of S. matsudana, gradually increasing with increased $\mathrm{Cd}$ concentrations and prolonged treatment times. The root was the main organ for absorbing and accumulating $\mathrm{Cd}$. $\mathrm{Cd}$ inhibited the accumulation of $\mathrm{Fe}, \mathrm{Zn}, \mathrm{Mn}$, and $\mathrm{Cu}$. In addition, the activities of antioxidant enzymes and the contents of reactive oxygen species were also changed by different concentrations of $\mathrm{Cd}$. The results obtained here can provide scientific and objective data for the use of S. matsudana in the remediation of Cd-contaminated soil.
\end{abstract}

Keywords: Salix matsudana Koidz, cadmium, minerals metabolism, antioxidant enzymes, reactive oxygen species (ROS)

\section{Introduction}

Nowadays, heavy metal pollution of soils has become a serious environmental concern and a potential threat to human health. Cadmium (Cd) is one of the most toxic nonessential elements for plants. High Cd concentrations in soils inhibit photosynthesis and growth as well as diminish water and nutrient uptake [1]. Normally, heavy metals only change their morphology and valence when entering the environment. They cannot be degraded biologically and are difficult to clean up. A clean and effective method of removing heavy metals from soil,

*e-mail: liuxiangjuntsd@163.com called phytoremediation, has been widely studied [2]. Plants are essential components in ecosystems because they transfer elements from the abiotic environment to the biotic one [3]. Some woody plants are widely used in phytoremediation, which could absorb, accumulate, and transport heavy metals to roots, stems, branches, and leaves of woody plants [4]. All willow species can accumulate high concentrations of $\mathrm{Cd}$. They can serve as a prospecting guide for metal ions and be utilized in phytoremediation of heavy-metal polluted soils [5].

Salix matsudana Koidz is a fast-growing, productive, and deeply rooted tree of the willow species that adapts to temperate region climatic conditions and has the ability to tolerate high $\mathrm{Cd}[4,6]$. Therefore, it has been discovered that $\mathrm{Cd}$ is concentrated by $S$. matsudana, 
which is believed to be a comparatively simple and easy method relative to simulating multi-metal pollution in hydroponic conditions [7]. It is of vital importance to explore the reaction mechanism of $S$. matsudana exposed to different $\mathrm{Cd}$ concentrations. The inhibition of photosynthesis leads to the accumulation of reduced plastoquinone, ferredoxin, and triplet state chlorophyll, which in turn facilitates the production of reactive oxygen species (ROS) [8]. ROS is identified as an indispensable process when plants have normal aerobic metabolism. It exists in the form of four major types, including singlet oxygen $\left({ }^{1} \mathrm{O}_{2}\right)$, superoxide $\left(\mathrm{O}_{2}^{-}\right)$, hydrogen peroxide $\left(\mathrm{H}_{2} \mathrm{O}_{2}\right)$, and hydroxyl radical $\left(\mathrm{OH}^{-}\right)$[9]. ROS accumulation aggravates membrane lipid peroxidation and oxidative damage [10-11]. Antioxidant enzymes eliminate ROS and act as a set of antioxidant enzymatic defense systems [12]. Cd can inhibit the metabolism processes such as photosynthesis, carbohydrate and nitrate metabolism, water balance, and DNA and lipid matrix, resulting in growth inhibition, morphological alterations, and plant senescence or even death [6,13]. Cd interferes with the uptake, transport, and use of different macro- and micronutrients such as zinc ( $\mathrm{Zn})$, iron $(\mathrm{Fe})$, manganese $(\mathrm{Mn})$, and selenium (Se) [6, 14].

In order to understand the physiological and biochemical changes mechanism and the resistance mechanism of $S$. matsudana to $\mathrm{Cd}$, the effects of $\mathrm{Cd}$ on mineral metabolism, activities of antioxidant enzymes, and ROS contents in S. matsudana under different concentrations of $\mathrm{Cd}$ stress were studied in this investigation. The results obtained here can provide scientific and objective data for the use of S. matsudana in the remediation of $\mathrm{Cd}$-contaminated soil.

\section{Material and Methods}

\section{Plant Material and Growth Conditions}

Healthy and fresh woody cuttings (25 cm long) were chosen from $S$. matsudana grown in the campus of Tianjin Normal University, Tianjin, China. They were immersed into four plastic containers with $2.5 \mathrm{~L}$ half Hoagland's nutrient solution mixed 0, 10, 50, and $100 \mu \mathrm{mol} / \mathrm{L} \mathrm{CdCl}_{2}$ for $28 \mathrm{~d}$ at a constant temperature, respectively. Hoagland's solution was composed of $0.5 \mathrm{~mol} / \mathrm{L} \quad \mathrm{Ca}\left(\mathrm{NO}_{3}\right)_{2}, \quad 0.5 \mathrm{~mol} / \mathrm{L} \quad \mathrm{KNO}_{3}, \quad 0.1 \mathrm{~mol} / \mathrm{L}$ $\mathrm{KH}_{2} \mathrm{PO}_{4}, \quad 0.1 \mathrm{~mol} / \mathrm{L} \quad \mathrm{MgSO}_{4} \cdot 7 \mathrm{H}_{2} \mathrm{O}, \quad 10 \mathrm{mmol} / \mathrm{L}$ $\mathrm{FeCl}_{3} \cdot 6 \mathrm{H}_{2} \mathrm{O}, 10 \mathrm{mmol} / \mathrm{L} \mathrm{Na}$-EDTA, $50 \mathrm{mmol} / \mathrm{L} \mathrm{H}_{3} \mathrm{BO}_{3}$, $4.5 \mathrm{mmol} / \mathrm{L} \quad \mathrm{MnCl}_{4} \cdot 4 \mathrm{H}_{2} \mathrm{O}, 0.3 \mu \mathrm{mol} / \mathrm{L} \quad \mathrm{CuSO}_{4} \cdot 5 \mathrm{H}_{2} \mathrm{O}$, $0.1 \mathrm{mmol} / \mathrm{L} \quad\left(\mathrm{NH}_{4}\right)_{6} \mathrm{Mo}_{7} \mathrm{O}_{24} \cdot 7 \mathrm{H}_{2} \mathrm{O}$, and $3.8 \mathrm{mmol} / \mathrm{L}$ $\mathrm{ZnSO}_{4} \cdot 7 \mathrm{H}_{2} \mathrm{O}$, adjusted to $\mathrm{pH} 5.5$. The solutions were aerated by pumps and changed regularly every $7 \mathrm{~d}$. And in the four treatment groups, the plant heights and root lengths were measured by the same ruler at the end of each time interval $(7 \mathrm{~d})$. All treatments were done in five replicates.

\section{Estimating Total Cd and Several Minerals}

Ten plants from control and each treatment were harvested at the end of each time interval $(7 \mathrm{~d})$. These plants, which were washed thoroughly with deionized water, were divided into roots, new stems, leaves, xylem of old stems, and phloem of old stems. All plant samples were dried to a constant weight $\left(45^{\circ} \mathrm{C}\right.$ for $3 \mathrm{~d}$, $80^{\circ} \mathrm{C}$ for $1 \mathrm{~d}$, and $105^{\circ} \mathrm{C}$ for $12 \mathrm{~h}$ ) and prepared using the wet-digestion method using concentrated nitric acid $\left(\mathrm{HNO}_{3}\right)$ and perchloric acid $\left(\mathrm{HClO}_{4}\right)$ [13] (Wu et al., 2017). Concentrations of $\mathrm{Cd}, \mathrm{Cu}, \mathrm{Fe}, \mathrm{Mn}$, and $\mathrm{Zn}$ were measured using inductively coupled plasma atomic emission spectrometry (ICP-AES, Leeman Labs Inc., New Hampshire, USA).

\section{Analysis of the Activities of Antioxidant Enzymes}

Fresh leaves $(0.1 \mathrm{~g})$ and roots $(0.05 \mathrm{~g})$ were harvested and washed with deionized water. These samples were ground into homogenates with $5 \mathrm{~mL}$ chilled sodium phosphate buffer $(50 \mathrm{mmol} / \mathrm{L}, \mathrm{pH} 7.8)$ at the end of each time interval $(7 \mathrm{~d})$. The homogenates were centrifuged at $12,000 \mathrm{rpm}$ for $15 \mathrm{~min}$. The supernatants were stored at $4^{\circ} \mathrm{C}$ and applied to analyzing the activities of superoxide dismutase (SOD), peroxidase (POD), and catalase (CAT).

\section{SOD Assay}

The SOD activity was estimated according to the method of $\mathrm{Wu}$ et al. (2017). The reaction mixture consisted of $81 \mathrm{~mL}$ methionine, $60 \mu \mathrm{L}$ EDTA-Na $2,0.3 \mathrm{~mL}$ riboflavin, $3 \mathrm{~mL}$ nitroblue tetrazolium chloride (NBT), and $5.64 \mathrm{~mL}$ sodium phosphate buffer $(50 \mathrm{mmol} / \mathrm{L}, \mathrm{pH}$ 7.8). The reaction started by placing tubes below two $15 \mathrm{~W}$ fluorescent lamps for $12 \mathrm{~min}$. Absorbance was recorded at $560 \mathrm{~nm}$ using a $\mathrm{UV}-\mathrm{Vis}$ spectrophotometer (UV-2550, Shimadzu, Kyoto, Japan). One unit of enzyme activity was defined as the quantity of the SOD required to produce a $50 \%$ inhibition of reduction of NBT under the experimental conditions, and the specific enzyme activity was expressed as units per $g$ fresh weight of roots and leaves (FW). All steps were kept in the dark.

\section{POD Assay}

The reaction mixtures were composed of $100 \mathrm{~mL}$ sodium phosphate buffer ( $0.1 \mathrm{M}, \mathrm{pH} 6.0), 50 \mu \mathrm{L}$ guaiacol, and $38 \mu \mathrm{L} \mathrm{H}_{2} \mathrm{O}_{2}(30 \%)$. The absorbance was measured immediately at $470 \mathrm{~nm}$ at $0.5 \mathrm{~min}$ intervals up to $2 \mathrm{~min}$ using a UV-Vis spectrophotometer (UV-2550, Shimadzu Japan) after enzyme extract was added to the reaction mixture. Enzyme-specific activity is defined as units (one peroxidase activity unit defined as absorbance at $470 \mathrm{~nm}$ changes per minute) per $\mathrm{g}$ of FW [15]. 


\section{CAT Assay}

The activity of CAT was measured instantly when $200 \mu \mathrm{L}$ enzyme extract and $300 \mu \mathrm{L} \mathrm{H}_{2} \mathrm{O}_{2}(0.1 \mathrm{~mol} / \mathrm{L})$ were added to the reaction mixture containing $1.5 \mathrm{~mL}$ sodium phosphate buffer $(50 \mathrm{mmol} / \mathrm{L}, \mathrm{pH} 7.8)$ and $1 \mathrm{~mL}$ deionized water. The method of reading the results was the same as POD. However, the absorbance was monitored at $240 \mathrm{~nm}$ until $\mathrm{H}_{2} \mathrm{O}_{2}$ was consumed completely. Activity was expressed as units (one catalase activity unit defined as absorbance at $240 \mathrm{~nm}$ changes per minute) per $\mathrm{g}$ of fresh weight [15].

\section{Analysis of Reactive Oxygen Species}

$$
\mathrm{O}_{2}^{-} \text {Assay }
$$

Fresh roots $(0.2 \mathrm{~g})$ and leaves $(0.2 \mathrm{~g})$ were reaped and homogenized in $2 \mathrm{~mL}$ sodium phosphate buffer $(50 \mathrm{mmol} / \mathrm{L}, \mathrm{pH} 7.8)$ with a pestle and mortar at the end of each time interval $(7 \mathrm{~d})$ of the $\mathrm{Cd}$ treatment. Homogenates were centrifuged at $12,000 \mathrm{rpm}$ for $15 \mathrm{~min}$. The supernatant $(0.5 \mathrm{~mL})$ was added to two kinds of reagents, including $0.5 \mathrm{~mL}$ sodium phosphate buffer $(50 \mathrm{mmol} / \mathrm{L}, \mathrm{pH} 7.8)$ and $1 \mathrm{~mL}$ hydroxylamine hydrochloride $(1 \mathrm{mmol} / \mathrm{L})$. After the mixture reacted completely for $60 \mathrm{~min}$ at $25^{\circ} \mathrm{C}, 1 \mathrm{~mL}$ sulphanilic acid $(17 \mathrm{mmol} / \mathrm{L})$ and $1 \mathrm{~mL} \alpha$-naphthylamine $(7 \mathrm{mmol} / \mathrm{L})$ were fully integrated into the reaction system. The whole reaction system continued to react for $20 \mathrm{~min}$ at $25^{\circ} \mathrm{C}$ and were mixed with $4 \mathrm{~mL}$ chloroform. Pink supernatant was obtained and centrifuged at 12,000 rpm for $3 \mathrm{~min}$. Absorbance was recorded at $530 \mathrm{~nm}$ using a UV-Vis spectrophotometer (UV-2550, Shimadzu, Kyoto, Japan). The reaction of oxidation hydroxylamine was expressed as the content of $\mathrm{O}_{2}^{-}$in $\mathrm{nmol} / \mathrm{L}$ per $\mathrm{g}$ of fresh weight [13].

a)

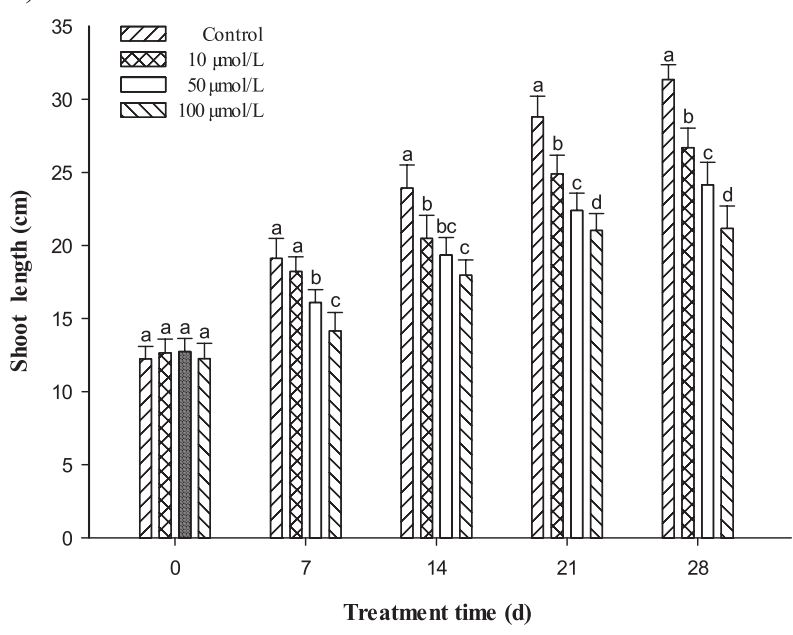

$$
\mathrm{H}_{2} \mathrm{O}_{2} \text { Assay }
$$

Fresh roots $(0.5 \mathrm{~g})$ and leaves $(0.5 \mathrm{~g})$ were harvested and homogenized in $5 \mathrm{~mL}$ cooling acetone at the end of each time interval ( $7 \mathrm{~d}$ ) of the $\mathrm{Cd}$ treatment. Homogenates were centrifuged at $12,000 \mathrm{rpm}$ for $20 \mathrm{~min}$. Two kinds of reagents contained $0.1 \mathrm{~mL}$ titanium sulphate $(5 \%)$ and $0.2 \mathrm{~mL}$ concentrated ammonia water were added to the supernatant $(1 \mathrm{~mL})$. The reaction mixture was centrifuged at 12,000 rpm for $15 \mathrm{~min}$. The sediments were washed a few times by adding cooling acetone until the pigmentum of sediments disappeared. Finally, the sediments and $5 \mathrm{~mL}$ sulfuric acid $(2 \mathrm{~mol} / \mathrm{L})$ were completely dissolved. The absorbance of mixture was surveyed at $415 \mathrm{~nm}$ using a UV-Vis spectrophotometer (UV-2550, Shimadzu, Kyoto, Japan). The peroxide was expressed as the content of $\mathrm{H}_{2} \mathrm{O}_{2}$ in nmol/L per $\mathrm{g}$ of fresh weight [13].

\section{Statistical Analysis}

Each treatment was triplicated for statistical validity. Data from this investigation were analyzed with standard statistical software (Sigma Plot 10.0) using means \pm standard error (SE). For equality of averages the t-test was applied. Results were considered statistically significant at $P<0.05$.

\section{Results}

\section{Macroscopic Effects of Cd Treatment on Plant Growth}

The different concentrations of $\mathrm{Cd}$ and treatment time had a great effect on plant height and root length. The leaves of $S$. matsudana exhibited chlorosis and b)

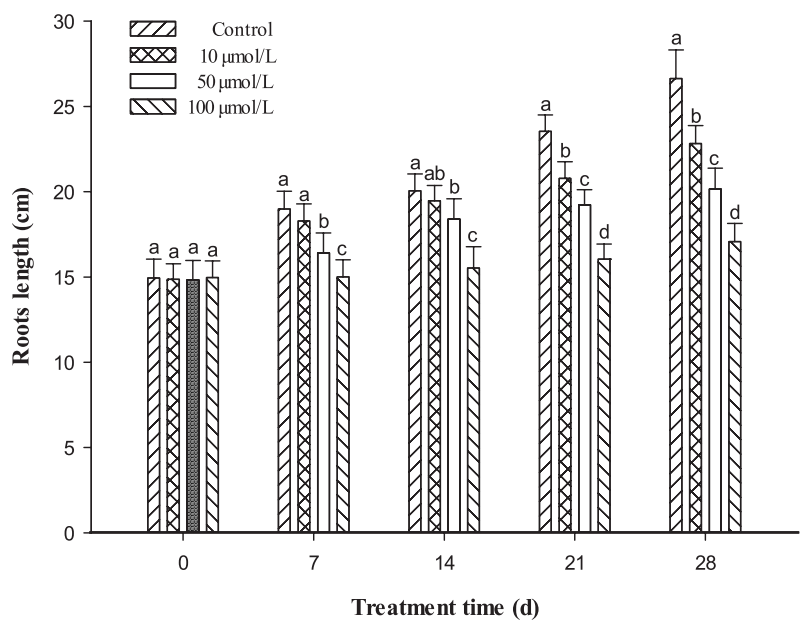

Fig. 1. Effects of different Cd concentrations on plant height and root length of S. matsudana under different Cd concentrations for $0,7,14,21$ and $28 \mathrm{~d}$. Error bars represent $\mathrm{SE}$ of the mean, $\mathrm{n}=5$. Values with different letters differ significantly from each other $(\mathrm{P}<0.05, t$-test). 
Table $1 \mathrm{Cd}$ accumulation in different organs of S. matsudana after treatments with different concentrations and duration of Cd.

\begin{tabular}{|c|c|c|c|c|c|c|c|}
\hline \multirow{2}{*}{$\begin{array}{l}\text { Time } \\
\text { (d) }\end{array}$} & \multirow{2}{*}{$\begin{array}{l}\text { Treatment } \\
(\mu \mathrm{mol} / \mathrm{L})\end{array}$} & \multicolumn{5}{|c|}{$\mathrm{Cd}(\mu \mathrm{g} / \mathrm{g}, \mathrm{DW} \pm \mathrm{SE})$} & \multirow{2}{*}{$\begin{array}{l}\mathrm{TF} \\
(\%)\end{array}$} \\
\hline & & Root & New stem & Leaf & Xylem of old stem & Phloem of old stem & \\
\hline \multirow{4}{*}{7} & 0 & $0.00 \mathrm{a}$ & $0.00 \mathrm{a}$ & $0.00 \mathrm{a}$ & $0.00 \mathrm{a}$ & $0.00 \mathrm{a}$ & 0 \\
\hline & 10 & $324.24 \pm 60.26 \mathrm{~b}$ & $46.24 \pm 5.87 \mathrm{~b}$ & $10.84 \pm 1.37 \mathrm{~b}$ & $11.03 \pm 0.98 \mathrm{~b}$ & $49.52 \pm 4.42 b$ & 26.6 \\
\hline & 50 & $636.65 \pm 83.21 \mathrm{c}$ & $124.94 \pm 7.63 \mathrm{c}$ & $24.81 \pm 2.35 \mathrm{c}$ & $16.44 \pm 0.68 b$ & $58.01 \pm 4.89 \mathrm{~b}$ & 26.0 \\
\hline & 100 & $1643.73 \pm 90.47 \mathrm{~d}$ & $148.83 \pm 7.97 \mathrm{c}$ & $59.65 \pm 2.09 \mathrm{~d}$ & $26.34 \pm 2.72 \mathrm{c}$ & $91.89 \pm 5.24 \mathrm{c}$ & 16.6 \\
\hline \multirow{4}{*}{14} & 0 & $0.00 \mathrm{a}$ & $0.00 \mathrm{a}$ & $0.00 \mathrm{a}$ & $0.00 \mathrm{a}$ & $0.00 \mathrm{a}$ & 0 \\
\hline & 10 & $568.93 \pm 82.19 b$ & $95.21 \pm 6.31 \mathrm{~b}$ & $29.85 \pm 1.59 b$ & $15.13 \pm 0.96 \mathrm{~b}$ & $83.33 \pm 5.59 b$ & 28.2 \\
\hline & 50 & $1232.26 \pm 93.59 \mathrm{c}$ & $126.80 \pm 7.89 \mathrm{c}$ & $45.64 \pm 2.89 \mathrm{c}$ & $54.76 \pm 3.63 \mathrm{c}$ & $111.83 \pm 6.15 \mathrm{c}$ & 21.6 \\
\hline & 100 & $2602.41 \pm 195.57 \mathrm{~d}$ & $163.38 \pm 8.34 \mathrm{~d}$ & $65.18 \pm 2.27 \mathrm{~d}$ & $89.66 \pm 3.65 \mathrm{~d}$ & $137.17 \pm 6.34 d$ & 14.9 \\
\hline \multirow{4}{*}{21} & 0 & $0.00 \mathrm{a}$ & $0.00 \mathrm{a}$ & $0.00 \mathrm{a}$ & $0.00 \mathrm{a}$ & $0.00 \mathrm{a}$ & 0 \\
\hline & 10 & $631.06 \pm 86.29 b$ & $120.86 \pm 7.59 b$ & $56.80 \pm 3.37 \mathrm{~b}$ & $16.21 \pm 0.79 b$ & $106.68 \pm 5.83 b$ & 32.3 \\
\hline & 50 & $1508.30 \pm 94.58 \mathrm{c}$ & $179.94 \pm 8.58 \mathrm{c}$ & $62.89 \pm 3.02 b$ & $54.94 \pm 3.75 \mathrm{c}$ & $133.92 \pm 6.58 \mathrm{c}$ & 22.3 \\
\hline & 100 & $2769.62 \pm 196.27 d$ & $201.61 \pm 8.86 \mathrm{c}$ & $77.63 \pm 2.49 \mathrm{c}$ & $98.35 \pm 4.76 \mathrm{~d}$ & $161.25 \pm 6.55 \mathrm{~d}$ & 16.9 \\
\hline \multirow{4}{*}{28} & 0 & $0.00 \mathrm{a}$ & $0.00 \mathrm{a}$ & $0.00 \mathrm{a}$ & $0.00 \mathrm{a}$ & $0.00 \mathrm{a}$ & 0 \\
\hline & 10 & $759.53 \pm 93.58 b$ & $129.94 \pm 7.23 b$ & $60.83 \pm 1.08 b$ & $17.32 \pm 1.08 b$ & $120.56 \pm 6.25 b$ & 30.2 \\
\hline & 50 & $1817.04 \pm 105.28 \mathrm{c}$ & $214.37 \pm 8.69 \mathrm{c}$ & $84.67 \pm 3.89 c$ & $58.39 \pm 3.89 \mathrm{c}$ & $154.04 \pm 7.01 \mathrm{c}$ & 22.0 \\
\hline & 100 & $2984.54 \pm 198.89 d$ & $253.24 \pm 9.25 \mathrm{~d}$ & $103.75 \pm 5.25 \mathrm{~d}$ & $129.36 \pm 5.25 \mathrm{~d}$ & $181.59 \pm 7.56 \mathrm{~d}$ & 18.3 \\
\hline
\end{tabular}

the roots become black after $28 \mathrm{~d}$ of exposure to $100 \mu \mathrm{mol} / \mathrm{L} \mathrm{Cd}$. At $10 \mu \mathrm{mol} / \mathrm{L} \mathrm{Cd}$ there were slight effects on leaf growth during the whole growth course. In comparison with control, the plant height of the $S$. matsudana seedlings treated with $10 \mu \mathrm{mol} / \mathrm{L} \mathrm{Cd}$ was inhibited at the $28^{\text {th }} \mathrm{d}$. At the same treated time, the plant height in the seedlings exposed to 50 and $100 \mu \mathrm{mol} / \mathrm{L}$ $\mathrm{Cd}$ had obvious alterations in contrast with control. The growth trend was suppressed during the whole course of growth (Fig. 1a). The root length of plants treated with 10, 50 , and $100 \mu \mathrm{mol} / \mathrm{L} \mathrm{Cd}$ were inhibited when compared to control during the whole course growth. The inhibition degree was more and more serious with increasing the concentration of $\mathrm{Cd}$ and treatment time (Fig. 1b). The roots of $S$. matsudana were more sensitive than the leaves under Cd stress.

\section{Cd Uptake and Accumulation in Different Organs}

The uptake and accumulation of $\mathrm{Cd}$ amount in $S$. matsudana roots, new stems, leaves, xylem of old stems, and phloem of old stems varied with $\mathrm{Cd}$ concentration and treatment time. As shown in Table 1, the organs of $S$. matsudana in the control group had no detectable $\mathrm{Cd}$, and levels of $\mathrm{Cd}$ accumulation were enhanced significantly $(P<0.05)$ with increasing $\mathrm{Cd}$ concentration and expanding duration of treatment. The root was the initial organ of $\mathrm{Cd}$ entering plant, and has an obvious enrichment effect of $\mathrm{Cd}$. The $\mathrm{Cd}$ content in roots reached the maximum value of $2984.54 \mu \mathrm{g} / \mathrm{g}$ after 28 days of treatment. The levels of $\mathrm{Cd}$ in $S$. matsudana were in the order as follows: roots $>$ phloem of old stems $>$ new stems $>$ xylem of old stems $>$ leaves when treated with $10 \mu \mathrm{mol} / \mathrm{L}$ for $7 \mathrm{~d}$, roots $>$ new stems $>$ phloem of old stems $>$ leaves $>$ xylem of old stems at $50 \mu \mathrm{mol} / \mathrm{L} \mathrm{Cd}$ during nearly all course growth, and roots $>$ new stems $>$ phloem of old stems $>$ xylem of old stems $>$ leaves at $100 \mu \mathrm{mol} / \mathrm{L} \mathrm{Cd}$ after the $14^{\text {th }} \mathrm{d}$. The translocation factor(TF) (the percentage of $\mathrm{Cd}$ from underground to the ground part) of $S$. matsudana in $10 \mu \mathrm{mol} / \mathrm{L} \mathrm{Cd}$ treatment group was $26.6 \%$ after $7 \mathrm{~d}, 28.2 \%$ after $14 \mathrm{~d}$, $32.3 \%$ after $21 \mathrm{~d}$, and $30.2 \%$ after $28 \mathrm{~d}$. TF were $26 \%$, $21.6 \%, 22.3 \%$, and $22 \%$ under $50 \mu \mathrm{mol} / \mathrm{L} \mathrm{Cd}$ stress for $7-28 \mathrm{~d}$, and $16.6 \%$ and $18.3 \%$, respectively, in $100 \mu \mathrm{mol} / \mathrm{L}$ Cd treatment group for $7 \mathrm{~d}$ and $28 \mathrm{~d}$.

\section{Effects of $\mathrm{Cd}$ on $\mathrm{Cu}, \mathrm{Fe}, \mathrm{Mn}$, and $\mathrm{Zn}$ Contents in Different Organs}

The uptake and distribution of $\mathrm{Cu}, \mathrm{Fe}, \mathrm{Mn}$, and $\mathrm{Zn}$ in $S$. matsudana were affected by different concentrations of Cd solution (Table 2-5). The results in Table 2 indicated that a low concentration of $\mathrm{Cd}(10 \mu \mathrm{mol} / \mathrm{L})$ was able to promote the uptake and accumulation of $\mathrm{Cu}$ in contrast with control. At $100 \mu \mathrm{mol} / \mathrm{L} \mathrm{Cd}$, there were inhibitory effects on absorbing $\mathrm{Cu}$ in new stems and xylem of old stems. Table 3 showed that the uptake and accumulation of Fe in the organs were inhibited significantly $(P<0.05)$ under $\mathrm{Cd}$ stress, and the inhibition was stronger and 
Table 2 Effect of different concentrations $\mathrm{Cd}$ on $\mathrm{Cu}$ contents in the different organs of S. matsudana.

\begin{tabular}{|c|c|c|c|c|c|c|}
\hline \multirow{2}{*}{$\begin{array}{l}\text { Time } \\
\text { (d) }\end{array}$} & \multirow{2}{*}{$\begin{array}{l}\text { Treatment } \\
(\mu \mathrm{mol} / \mathrm{L})\end{array}$} & \multicolumn{5}{|c|}{ Organs $(\mu \mathrm{g} / \mathrm{g}, \mathrm{DW} \pm \mathrm{SE})$} \\
\hline & & Roots & New stems & Leaves & Xylem of old stems & Phloem of old stems \\
\hline \multirow{4}{*}{7} & 0 & $18.48 \pm 1.37 \mathrm{a}$ & $21.50 \pm 0.61 \mathrm{a}$ & $24.74 \pm 1.45 \mathrm{a}$ & $12.98 \pm 1.34 \mathrm{a}$ & $16.30 \pm 1.21 \mathrm{a}$ \\
\hline & 10 & $23.09 \pm 1.75 \mathrm{ab}$ & $22.82 \pm 1.64 \mathrm{ab}$ & $21.57 \pm 1.38 \mathrm{a}$ & $23.20 \pm 1.46 b$ & $19.67 \pm 1.59 \mathrm{a}$ \\
\hline & 50 & $26.76 \pm 1.38 b$ & $26.09 \pm 1.64 b$ & $24.55 \pm 0.85 \mathrm{a}$ & $18.76 \pm 1.63 \mathrm{c}$ & $15.20 \pm 1.37 \mathrm{a}$ \\
\hline & 100 & $21.67 \pm 1.72 \mathrm{c}$ & $24.67 \pm 1.72 \mathrm{ab}$ & $20.28 \pm 1.58 \mathrm{a}$ & $12.87 \pm 1.32 \mathrm{a}$ & $10.63 \pm 1.35 b$ \\
\hline \multirow{4}{*}{14} & 0 & $14.18 \pm 0.82 \mathrm{a}$ & $16.31 \pm 1.27 \mathrm{a}$ & $16.93 \pm 1.02 \mathrm{a}$ & $20.10 \pm 1.74 \mathrm{a}$ & $16.35 \pm 1.38 \mathrm{a}$ \\
\hline & 10 & $30.63 \pm 1.38 b$ & $32.62 \pm 1.59 b$ & $17.52 \pm 1.64 \mathrm{a}$ & $22.65 \pm 0.95 \mathrm{a}$ & $17.77 \pm 1.54 \mathrm{a}$ \\
\hline & 50 & $28.17 \pm 1.27 \mathrm{~b}$ & $22.66 \pm 0.92 \mathrm{c}$ & $21.75 \pm 0.65 b$ & $17.95 \pm 2.71 \mathrm{a}$ & $16.60 \pm 1.38 \mathrm{a}$ \\
\hline & 100 & $27.56 \pm 1.16 b$ & $14.08 \pm 1.32 \mathrm{a}$ & $18.87 \pm 1.39 \mathrm{a}$ & $11.28 \pm 0.91 \mathrm{~b}$ & $11.47 \pm 0.63 b$ \\
\hline \multirow{4}{*}{21} & 0 & $17.63 \pm 0.68 \mathrm{a}$ & $12.49 \pm 0.55 \mathrm{a}$ & $13.62 \pm 1.32 \mathrm{a}$ & $11.92 \pm 0.38 \mathrm{a}$ & $15.14 \pm 1.20 \mathrm{a}$ \\
\hline & 10 & $34.56 \pm 1.04 b$ & $28.52 \pm 1.19 b$ & $13.65 \pm 1.3 \mathrm{a} 7$ & $16.52 \pm 0.82 b$ & $17.02 \pm 0.16 \mathrm{a}$ \\
\hline & 50 & $32.70 \pm 1.76 b$ & $20.64 \pm 1.83 c$ & $21.67 \pm 1.57 \mathrm{~b}$ & $17.39 \pm 0.69 b$ & $16.07 \pm 0.76 \mathrm{a}$ \\
\hline & 100 & $26.69 \pm 1.35 \mathrm{c}$ & $13.85 \pm 1.28 \mathrm{~d}$ & $13.31 \pm 1.27 \mathrm{a}$ & $10.80 \pm 0.80 \mathrm{a}$ & $16.13 \pm 0.69 \mathrm{a}$ \\
\hline \multirow{4}{*}{28} & 0 & $16.34 \pm 1.82 \mathrm{a}$ & $13.85 \pm 1.06 \mathrm{a}$ & $13.29 \pm 1.43 \mathrm{a}$ & $10.73 \pm 0.48 \mathrm{a}$ & $12.89 \pm 1.07 \mathrm{a}$ \\
\hline & 10 & $27.86 \pm 1.41 b$ & $19.65 \pm 0.78 b$ & $12.05 \pm 0.79 \mathrm{a}$ & $12.00 \pm 061 \mathrm{a}$ & $14.84 \pm 0.67 \mathrm{a}$ \\
\hline & 50 & $33.02 \pm 1.81 \mathrm{c}$ & $16.40 \pm 0.67 b$ & $18.37 \pm 0.85 b$ & $17.40 \pm 0.67 b$ & $15.93 \pm 2.41 \mathrm{a}$ \\
\hline & 100 & $27.65 \pm 0.34 b$ & $10.26 \pm 0.46 \mathrm{a}$ & $12.21 \pm 0.73 a$ & $9.41 \pm 0.43 \mathrm{a}$ & $14.26 \pm 0.86 \mathrm{a}$ \\
\hline
\end{tabular}

Table 3 Effect of different concentrations Cd on Fe contents in the different organs of S. matsudana.

\begin{tabular}{|c|c|c|c|c|c|c|}
\hline \multirow{2}{*}{$\begin{array}{l}\text { Time } \\
\text { (d) }\end{array}$} & \multirow{2}{*}{$\begin{array}{l}\text { Treatment } \\
(\mu \mathrm{mol} / \mathrm{L})\end{array}$} & \multicolumn{5}{|c|}{ Organs $(\mu \mathrm{g} / \mathrm{g}, \mathrm{DW} \pm \mathrm{SE})$} \\
\hline & & Roots & New stems & Leaves & Xylem of old stems & Phloem of old stems \\
\hline \multirow{4}{*}{7} & 0 & $1260.47 \pm 56.21 \mathrm{a}$ & $1991.31 \pm 84.20 \mathrm{a}$ & $1420.18 \pm 36.87 \mathrm{a}$ & $911.59 \pm 12.63 \mathrm{a}$ & $1096.29 \pm 50.41 \mathrm{a}$ \\
\hline & 10 & $1449.04 \pm 25.53 b$ & $1872.13 \pm 16.52 b$ & $1123.31 \pm 12.64 b$ & $832.52 \pm 16.58 \mathrm{a}$ & $926.65 \pm 15.21 b$ \\
\hline & 50 & $619.17 \pm 18.96 \mathrm{c}$ & $471.14 \pm 14.23 \mathrm{c}$ & $385.32 \pm 12.27 \mathrm{c}$ & $405.29 \pm 12.68 b$ & $405.11 \pm 12.54 \mathrm{c}$ \\
\hline & 100 & $651.56 \pm 18.92 \mathrm{c}$ & $408.83 \pm 12.34 \mathrm{c}$ & $278.07 \pm 10.32 \mathrm{~d}$ & $192.01 \pm 8.97 \mathrm{c}$ & $360.87 \pm 10.56 \mathrm{c}$ \\
\hline \multirow{4}{*}{14} & 0 & $1146.82 \pm 26.97 \mathrm{a}$ & $1253.05 \pm 21.34 \mathrm{a}$ & $905.35 \pm 18.97 \mathrm{a}$ & $786.54 \pm 15.67 \mathrm{a}$ & $853.06 \pm 16.84 \mathrm{a}$ \\
\hline & 10 & $1209.90 \pm 12.64 \mathrm{a}$ & $931.89 \pm 11.68 b$ & $684.41 \pm 18.24 b$ & $621.65 \pm 12.10 \mathrm{~b}$ & $610.36 \pm 13.28 b$ \\
\hline & 50 & $603.09 \pm 12.64 b$ & $399.44 \pm 15.75 \mathrm{c}$ & $342.74 \pm 12.38 \mathrm{c}$ & $330.79 \pm 11.69 \mathrm{c}$ & $318.66 \pm 10.52 \mathrm{c}$ \\
\hline & 100 & $630.35 \pm 18.92 b$ & $214.83 \pm 10.20 \mathrm{~d}$ & $272.82 \pm 8.64 \mathrm{c}$ & $283.57 \pm 6.82 \mathrm{c}$ & $275.78 \pm 6.82 \mathrm{c}$ \\
\hline \multirow{4}{*}{21} & 0 & $1016.28 \pm 16.52 \mathrm{a}$ & $883.72 \pm 12.94 \mathrm{a}$ & $741.81 \pm 12.37 \mathrm{a}$ & $467.36 \pm 8.92 \mathrm{a}$ & $694.86 \pm 14.61 \mathrm{a}$ \\
\hline & 10 & $1103.21 \pm 63.24 \mathrm{a}$ & $665.52 \pm 36.57 \mathrm{~b}$ & $565.54 \pm 52.74 b$ & $309.86 \pm 7.86 b$ & $407.66 \pm 12.81 \mathrm{~b}$ \\
\hline & 50 & $525.01 \pm 12.85 b$ & $291.34 \pm 13.57 \mathrm{c}$ & $332.48 \pm 12.46 \mathrm{c}$ & $233.21 \pm 26.41 \mathrm{c}$ & $313.66 \pm 62.41 \mathrm{c}$ \\
\hline & 100 & $608.38 \pm 62.41 b$ & $199.77 \pm 16.24 d$ & $255.61 \pm 12.58 \mathrm{~d}$ & $243.15 \pm 9.61 \mathrm{c}$ & $248.28 \pm 21.17 \mathrm{~d}$ \\
\hline \multirow{4}{*}{28} & 0 & $832.00 \pm 16.74 a$ & $689.98 \pm 21.84 \mathrm{a}$ & $421.67 \pm 2.95 \mathrm{a}$ & $244.06 \pm 12.58 \mathrm{a}$ & $470.09 \pm 43.79 \mathrm{a}$ \\
\hline & 10 & $621.36 \pm 12.58 b$ & $641.44 \pm 13.47 \mathrm{a}$ & $355.58 \pm 10.46 b$ & $183.26 \pm 10.32 b$ & $347.66 \pm 10.55 \mathrm{a}$ \\
\hline & 50 & $554.14 \pm 12.57 \mathrm{bc}$ & $268.24 \pm 13.86 b$ & $275.55 \pm 10.73 \mathrm{c}$ & $158.46 \pm 10.82 \mathrm{bc}$ & $226.94 \pm 10.81 b$ \\
\hline & 100 & $495.19 \pm 10.85 \mathrm{c}$ & $135.27 \pm 16.79 \mathrm{c}$ & $188.49 \pm 13.82 \mathrm{~d}$ & $109.27 \pm 6.70 \mathrm{c}$ & $238.43 \pm 10.34 b$ \\
\hline
\end{tabular}


Table 4 Effect of different concentrations $\mathrm{Cd}$ on Mn contents in the different organs of S. matsudana.

\begin{tabular}{|c|c|c|c|c|c|c|}
\hline \multirow{2}{*}{$\begin{array}{l}\text { Time } \\
\text { (d) }\end{array}$} & \multirow{2}{*}{$\begin{array}{c}\text { Treatment( } \\
\mu \mathrm{mol} / \mathrm{L})\end{array}$} & \multicolumn{5}{|c|}{ Organs $(\mu \mathrm{g} / \mathrm{g}, \mathrm{DW} \pm \mathrm{SE})$} \\
\hline & & Roots & New stems & Leaves & Xylem of old stems & Phloem of old stems \\
\hline \multirow{4}{*}{7} & 0 & $43.42 \pm 3.25 \mathrm{a}$ & $40.16 \pm 2.48 \mathrm{a}$ & $68.46 \pm 3.63 \mathrm{a}$ & $22.25 \pm 1.84 \mathrm{a}$ & $35.78 \pm 2.10 \mathrm{a}$ \\
\hline & 10 & $111.76 \pm 8.94 \mathrm{~b}$ & $52.96 \pm 3.86 \mathrm{a}$ & $56.67 \pm 3.75 b$ & $19.55 \pm 1.98 \mathrm{a}$ & $46.81 \pm 3.42 b$ \\
\hline & 50 & $29.45 \pm 2.41 \mathrm{c}$ & $28.14 \pm 2.10 \mathrm{ab}$ & $44.12 \pm 3.12 \mathrm{c}$ & $19.40 \pm 2.15 \mathrm{a}$ & $24.57 \pm 2.34 \mathrm{c}$ \\
\hline & 100 & $16.63 \pm 1.22 \mathrm{~d}$ & $19.52 \pm 1.34 b$ & $29.49 \pm 2.47 \mathrm{~d}$ & $11.16 \pm 1.04 \mathrm{~b}$ & $9.18 \pm 1.41 \mathrm{~d}$ \\
\hline \multirow{4}{*}{14} & 0 & $45.08 \pm 3.42 \mathrm{a}$ & $36.86 \pm 2.03 \mathrm{a}$ & $55.28 \pm 3.67 \mathrm{a}$ & $16.50 \pm 1.79 \mathrm{a}$ & $34.64 \pm 2.63 \mathrm{a}$ \\
\hline & 10 & $74.67 \pm 5.43 b$ & $45.62 \pm 3.15 \mathrm{a}$ & $47.41 \pm 3.04 \mathrm{ab}$ & $33.10 \pm 2.36 \mathrm{~b}$ & $29.57 \pm 1.27 \mathrm{a}$ \\
\hline & 50 & $28.82 \pm 1.30 \mathrm{c}$ & $25.74 \pm 1.05 b$ & $43.67 \pm 2.74 b$ & $13.81 \pm 0.94 \mathrm{ac}$ & $23.14 \pm 1.22 b$ \\
\hline & 100 & $14.76 \pm 0.55 \mathrm{~d}$ & $18.94 \pm 0.84 \mathrm{c}$ & $23.07 \pm 1.24 \mathrm{c}$ & $10.40 \pm 0.67 \mathrm{c}$ & $8.04 \pm 0.51 \mathrm{c}$ \\
\hline \multirow{4}{*}{21} & 0 & $40.45 \pm 2.54 \mathrm{a}$ & $30.06 \pm 2.46 \mathrm{a}$ & $53.70 \pm 3.21 \mathrm{a}$ & $17.06 \pm 1.05 \mathrm{a}$ & $32.09 \pm 2.13 \mathrm{a}$ \\
\hline & 10 & $65.24 \pm 3.42 b$ & $37.55 \pm 2.16 \mathrm{~b}$ & $38.28 \pm 2.29 b$ & $25.42 \pm 1.64 \mathrm{~b}$ & $29.23 \pm 1.37 \mathrm{a}$ \\
\hline & 50 & $23.95 \pm 1.32 \mathrm{c}$ & $23.58 \pm 1.28 \mathrm{c}$ & $42.77 \pm 2.71 \mathrm{~b}$ & $14.20 \pm 0.64 \mathrm{a}$ & $20.90 \pm 0.83 b$ \\
\hline & 100 & $10.79 \pm 0.61 \mathrm{~d}$ & $10.97 \pm 0.45 \mathrm{~d}$ & $16.43 \pm 0.73 c$ & $8.00 \pm 0.24 \mathrm{c}$ & $5.76 \pm 0.18 \mathrm{c}$ \\
\hline \multirow{4}{*}{28} & 0 & $34.88 \pm 2.43 \mathrm{a}$ & $29.81 \pm 2.16 \mathrm{a}$ & $47.95 \pm 3.10 \mathrm{a}$ & $18.62 \pm 1.07 \mathrm{a}$ & $35.14 \pm 1.84 \mathrm{a}$ \\
\hline & 10 & $38.26 \pm 1.84 \mathrm{a}$ & $31.77 \pm 1.29 \mathrm{a}$ & $44.04 \pm 2.57 \mathrm{a}$ & $18.02 \pm 1.21 \mathrm{a}$ & $20.79 \pm 1.36 b$ \\
\hline & 50 & $22.08 \pm 1.23 b$ & $17.21 \pm 1.08 \mathrm{~b}$ & $32.49 \pm 1.87 \mathrm{~b}$ & $10.00 \pm 0.76 \mathrm{~b}$ & $7.03 \pm 0.24 \mathrm{c}$ \\
\hline & 100 & $2.73 \pm 0.12 \mathrm{c}$ & $9.92 \pm 0.37 \mathrm{c}$ & $13.82 \pm 0.78 \mathrm{c}$ & $7.05 \pm 0.16 \mathrm{~b}$ & $1.71 \pm 0.12 \mathrm{~d}$ \\
\hline
\end{tabular}

Table 5 Effect of different concentrations Cd on $\mathrm{Zn}$ contents in the different organs of S. matsudana.

\begin{tabular}{|c|c|c|c|c|c|c|}
\hline \multirow{2}{*}{$\begin{array}{l}\text { Time } \\
\text { (d) }\end{array}$} & \multirow{2}{*}{$\begin{array}{l}\text { Treatment } \\
(\mu \mathrm{mol} / \mathrm{L})\end{array}$} & \multicolumn{5}{|c|}{ Organs $(\mu \mathrm{g} / \mathrm{g}, \mathrm{DW} \pm \mathrm{SE})$} \\
\hline & & Roots & New stems & Leaves & Xylem of old stems & Phloem of old stems \\
\hline \multirow{4}{*}{7} & 0 & $90.64 \pm 6.46 \mathrm{a}$ & $152.58 \pm 7.17 \mathrm{a}$ & $120.57 \pm 9.79 a$ & $76.96 \pm 6.47 \mathrm{a}$ & $250.62 \pm 9.51 \mathrm{a}$ \\
\hline & 10 & $133.71 \pm 10.59 b$ & $207.25 \pm 10.64 b$ & $129.21 \pm 8.71 \mathrm{a}$ & $84.04 \pm 6.44 \mathrm{a}$ & $247.26 \pm 7.56 \mathrm{a}$ \\
\hline & 50 & $126.37 \pm 13.54 b$ & $161.31 \pm 12.64 \mathrm{a}$ & $162.51 \pm 14.47 \mathrm{~b}$ & $74.53 \pm 5.68 \mathrm{a}$ & $237.80 \pm 15.27 \mathrm{a}$ \\
\hline & 100 & $158.77 \pm 3.75 b$ & $173.53 \pm 9.24 \mathrm{a}$ & $141.20 \pm 3.45 \mathrm{c}$ & $67.87 \pm 3.75 \mathrm{a}$ & $229.91 \pm 12.64 \mathrm{a}$ \\
\hline \multirow{4}{*}{14} & 0 & $92.77 \pm 2.34 \mathrm{a}$ & $141.53 \pm 5.37 \mathrm{a}$ & $96.51 \pm 8.42 \mathrm{a}$ & $74.87 \pm 3.45 \mathrm{a}$ & $248.01 \pm 3.78 \mathrm{a}$ \\
\hline & 10 & $157.39 \pm 2.37 b$ & $158.98 \pm 6.72 \mathrm{a}$ & $111.67 \pm 3.42 \mathrm{a}$ & $60.00 \pm 1.37 \mathrm{~b}$ & $239.55 \pm 15.34 \mathrm{a}$ \\
\hline & 50 & $124.72 \pm 1.34 \mathrm{c}$ & $127.58 \pm 1.57 \mathrm{~b}$ & $130.32 \pm 2.30 \mathrm{~b}$ & $59.03 \pm 1.02 \mathrm{~b}$ & $227.11 \pm 12.09 \mathrm{a}$ \\
\hline & 100 & $111.06 \pm 1.85 \mathrm{c}$ & $126.77 \pm 1.24 b$ & $115.46 \pm 1.38 \mathrm{a}$ & $58.67 \pm 1.38 b$ & $226.22 \pm 13.01 \mathrm{a}$ \\
\hline \multirow{4}{*}{21} & 0 & $74.76 \pm 2.17 \mathrm{a}$ & $105.95 \pm 1.38 \mathrm{a}$ & $91.82 \pm 2.37 \mathrm{a}$ & $60.09 \pm 1.34 \mathrm{a}$ & $246.41 \pm 13.25 \mathrm{a}$ \\
\hline & 10 & $122.35 \pm 10.34 b$ & $135.54 \pm 10.58 \mathrm{a}$ & $102.35 \pm 1.35 \mathrm{a}$ & $58.13 \pm 1.36 \mathrm{a}$ & $219.55 \pm 10.38 \mathrm{a}$ \\
\hline & 50 & $119.76 \pm 9.65 b$ & $112.79 \pm 6.54 \mathrm{a}$ & $111.65 \pm 4.65 \mathrm{a}$ & $51.56 \pm 1.59 \mathrm{~b}$ & $214.21 \pm 6.24 b$ \\
\hline & 100 & $107.07 \pm 6.14 b$ & $118.66 \pm 5.37 \mathrm{a}$ & $99.76 \pm 4.65 \mathrm{a}$ & $40.39 \pm 3.54 \mathrm{c}$ & $210.73 \pm 3.54 b$ \\
\hline \multirow{4}{*}{28} & 0 & $66.64 \pm 1.37 \mathrm{a}$ & $87.23 \pm 1.52 \mathrm{a}$ & $82.08 \pm 1.45 \mathrm{a}$ & $47.38 \pm 1.38 \mathrm{a}$ & $204.81 \pm 10.34 \mathrm{a}$ \\
\hline & 10 & $103.39 \pm 6.37 \mathrm{~b}$ & $117.51 \pm 4.68 b$ & $84.4 \pm 1.38 \mathrm{a}$ & $52.09 \pm 2.20 \mathrm{a}$ & $190.23 \pm 4.38 \mathrm{ab}$ \\
\hline & 50 & $110.39 \pm 3.81 \mathrm{~b}$ & $81.16 \pm 2.37 \mathrm{a}$ & $80.01 \pm 2.41 \mathrm{a}$ & $50.24 \pm 1.35 \mathrm{a}$ & $188.70 \pm 6.27 b$ \\
\hline & 100 & $86.30 \pm 1.38 \mathrm{c}$ & $64.40 \pm 1.39 \mathrm{c}$ & $92.14 \pm 6.34 b$ & $44.09 \pm 1.25 \mathrm{a}$ & $137.95 \pm 4.85 \mathrm{c}$ \\
\hline
\end{tabular}


stronger with the elongation of treatment time, which was consistent with the phenomena of leaves turning yellow due to the lack of Fe (Table 3). After $10 \mu \mathrm{mol} / \mathrm{L}$ $\mathrm{Cd}$ treatment, the contents of $\mathrm{Mn}$ in roots and new stems gradually increased to a different extent, but were reduced under $50 \mu \mathrm{mol} / \mathrm{L}$ and $100 \mu \mathrm{mol} / \mathrm{L} \mathrm{Cd}$ in overall organs of $S$. matsudana, and the reduction increased with increasing $\mathrm{Cd}$ concentration when compared to control values (Table 4). Versus control, $\mathrm{Zn}$ contents in roots increased significantly and $\mathrm{Zn}$ contents in phloem of old stems decreased significantly under three $\mathrm{Cd}$ treatments $(10,50$, and $100 \mu \mathrm{mol} / \mathrm{L})$ during the whole treatment cycle. $\mathrm{Zn}$ levels in new stems were also affected by different concentrations of $\mathrm{Cd}$ in the nutrient solution. The general trend in new stems was that low concentrations of $\mathrm{Cd}$ promoted the $\mathrm{Zn}$ levels while high concentrations inhibited them. However, $\mathrm{Cd}$ had no impact on accumulating $\mathrm{Zn}$ in leaves and xylem of old stems (Table 5).

\section{Effects of Cd on the Activities of SOD, POD, and CAT}

The effects of Cd on SOD, POD, and CAT activities of roots and leaves in $S$. matsudana varied with the different concentrations of $\mathrm{Cd}$ (Fig. 2). The results showed that the SOD activity in leaves exposed to 10,50 , and $100 \mu \mathrm{mol} / \mathrm{L} \mathrm{Cd}$ and that in roots exposed to 50 and $100 \mu \mathrm{mol} / \mathrm{L} \mathrm{Cd}$ were observed to significantly improve during the whole treatment when compared with control (Figs 2a-b). However, the SOD activities in leaves had a sharp decline when treated with $100 \mu \mathrm{mol} / \mathrm{L} \mathrm{Cd}$ on the $28^{\text {th }} \mathrm{d}$ (Fig. 2a). The SOD activities in the seedlings exposed to $10 \mu \mathrm{mol} / \mathrm{L} \mathrm{Cd}$ for $14 \mathrm{~d}$ began to reduce significantly $(P<0.05)$ in comparison with that in control (Fig. 2b).

As shown in Fig. 2c, the POD activities in leaves exposed to 10 and $50 \mu \mathrm{mol} / \mathrm{L}$ at $7^{\text {th }} \mathrm{d}$ were slightly higher $(P<0.05)$ than that in control, but decreased significantly $(P<0.05)$ between 14 and $21 \mathrm{~d}$ of $\mathrm{Cd}$ exposure and were lower than that in control. The POD activities in leaves treated with $100 \mu \mathrm{mol} / \mathrm{L} \mathrm{Cd}$ and in roots treated with 10 , 50 , and $100 \mu \mathrm{mol} / \mathrm{L} \mathrm{Cd}$ were noted to be significantly higher $(P<0.05)$ than that in control (Fig. 2d). The increased percentage of POD activities was higher in roots than that in leaves during the $21 \mathrm{~d}$ of $\mathrm{Cd}$ exposure.

The CAT activities were quite different between leaves and roots. The CAT activities in leaves exposed to 10,50 , and $100 \mu \mathrm{mol} / \mathrm{L} \mathrm{Cd}$ were lower than those in control during the whole treatment (Fig. 2e). On the contrary, the CAT activities in roots had no obvious distinction between the treatments and control during the $21 \mathrm{~d}$ period of the experiment. The CAT activities in $\mathrm{Cd}$ treatments increased significantly and were far higher than that in control during the 21 to $28 \mathrm{~d}$ (Fig. 2f).

In summary, the SOD, POD, and CAT activities in roots and the SOD activities in leaves of $S$. matsudana could be improved under $\mathrm{Cd}$ stress. The ability to accelerate the antioxidant enzymes (SOD, POD, and
CAT) was stronger in high Cd concentration than in low concentration in S. matsudana under Cd stress.

Effects of $\mathrm{Cd}$ on the Contents of $\mathrm{O}_{2}^{-}$and $\mathrm{H}_{2} \mathrm{O}_{2}$

The contents of $\mathrm{O}_{2}^{-}$and $\mathrm{H}_{2} \mathrm{O}_{2}$ had a close connection with concentration of $\mathrm{Cd}$ and treatment time (Fig. 3). The $\mathrm{H}_{2} \mathrm{O}_{2}$ contents in leaves and roots saw a similar trend when treated with different $\mathrm{Cd}$ concentrations (Figs 3a-b). The $\mathrm{H}_{2} \mathrm{O}_{2}$ contents in leaves treated with 50 and $100 \mu \mathrm{mol} / \mathrm{L}$ $\mathrm{Cd}$ were greatly higher than that in control, but the $\mathrm{H}_{2} \mathrm{O}_{2}$ contents at $10 \mu \mathrm{mol} / \mathrm{L} \mathrm{Cd}$ were not significantly different from that in control. Cd was capable of promoting the production of $\mathrm{H}_{2} \mathrm{O}_{2}$ compared with control. In the leaves, the contents of $\mathrm{O}_{2}^{-}$in the seedlings exposed to 10 and $50 \mu \mathrm{mol} / \mathrm{L} \mathrm{Cd}$ were less than in control during the $14 \mathrm{~d}$ of treatment. At the $21^{\text {st }} \mathrm{d}$, the $\mathrm{O}_{2}{ }^{-}$contents were higher than that in control. At $100 \mu \mathrm{mol} / \mathrm{L} \mathrm{Cd}$ concentration, the $\mathrm{O}_{2}^{-}$content was increased significantly $(P<0.05)$ when compared with that in control during the entire 28-d treatment (Fig. 3c). The $\mathrm{O}_{2}{ }^{-}$contents in roots were all enhanced under 10, 50, and $100 \mu \mathrm{mol} / \mathrm{L} \mathrm{Cd}$ for 28 $\mathrm{d}$, and the $\mathrm{O}_{2}^{-}$contents increased with the increasing Cd concentration (Fig. 3d). Therefore, it seemed that $S$. matsudana had the ability to resist the low concentration of $\mathrm{Cd}$, whereas there was a limit to struggling against the high concentration of $\mathrm{Cd}$.

\section{Discussion}

As one of the most dangerous and extensively distributed pollutants, $\mathrm{Cd}$ had a severe threat to the environment and human health. Although $\mathrm{Cd}$ is not the essential element for plants, it is also readily taken in and accumulated by plants and influenced the normal metabolism of plants [16]. The most tangible effects of $\mathrm{Cd}$ toxicity in plants are stunted growth and leaf chlorosis $[6,17]$. In this investigation, the reductions of plant height and root length were observed with increasing $\mathrm{Cd}$ concentrations and extending the treatment time. After being stressed for a long time, the leaves of S. matsudana turned slightly yellow and the roots turned black and excreted mucus at high $\mathrm{Cd}$ concentrations.

A recent study has shown that heavy metal Cd can be accumulated in the order roots, stems, branches, and leaves. The Cd accumulation capability of different woody plants is different and that in different parts of the same kinds of woody plants are also different [4]. Concentrations of $\mathrm{Cd}$ and other elements are almost significantly higher in the roots than in above-ground tissues [18]. Data from the present investigation indicated that $S$. matsudana had the ability to accumulate $\mathrm{Cd}$ primarily in their roots (about $70 \%$ ), with lower concentrations in the shoots. However, $\mathrm{TF}$ increased with increasing the $\mathrm{Cd}$ concentration and prolonging the treatment time, and reached the maximum after $21 \mathrm{~d}$ of $\mathrm{Cd}$ stress. There are several definitions on hyperaccumulators [19-20]. Most recognized standard criteria were based on metal concentrations in 
aboveground tissues of plant material sampled from its natural habitat [21]. The currently accepted $0.01 \%(\mathrm{w} / \mathrm{w})$ $\mathrm{Cd}$ concentration in the shoot defines hyperaccumulation [22]. Data from the present investigation implied that $S$. matsudana could be efficient phytoextraction plants with a considerable ability to accumulate $\mathrm{Cd}$. This was in accordance with the findings of Zárubová et al. [23].
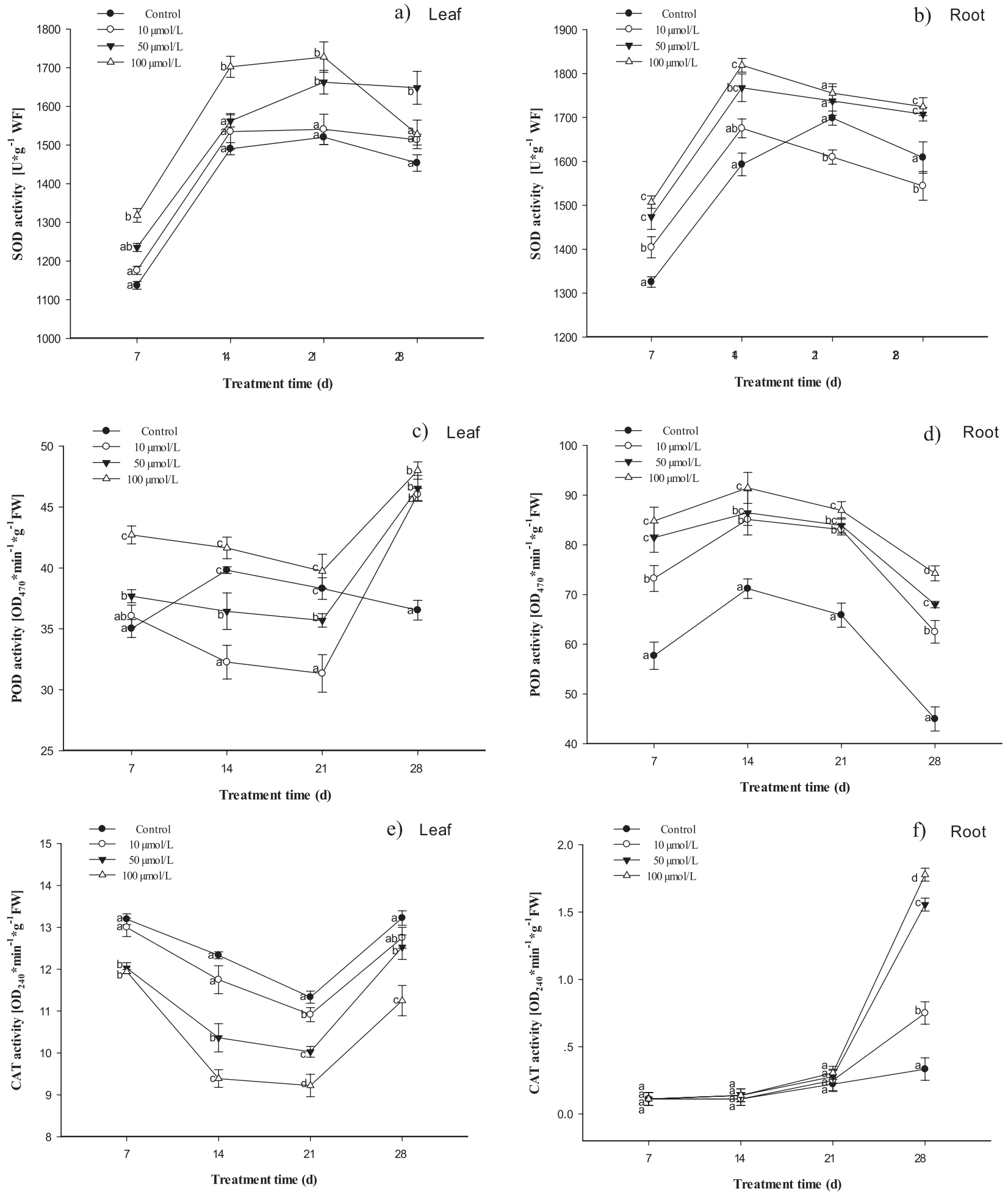

Fig. 2. Effect of different concentrations Cd on the activities of three antioxidant enzymes in leaves and roots of $S$. matsudana stressed for 7, 14, 21 and $28 \mathrm{~d}$. Vertical bars denote $\mathrm{SE}, \mathrm{n}=5$. Values with different letters differ significantly from each other $(\mathrm{P}<0.05$, $\mathrm{t}$-test $)$
Accumulating $\mathrm{Cd}$ to different organs had an obvious impact on the uptake of $\mathrm{Cu}, \mathrm{Fe}, \mathrm{Mn}$, and $\mathrm{Zn}$. Plants have a complex metal homeostasis network system that regulates the uptake and distribution of some basic elements in order to ensure the normal metabolic processes. The interactions among all the elements are well documented for herbaceous, woody, and hyperaccumulator plants

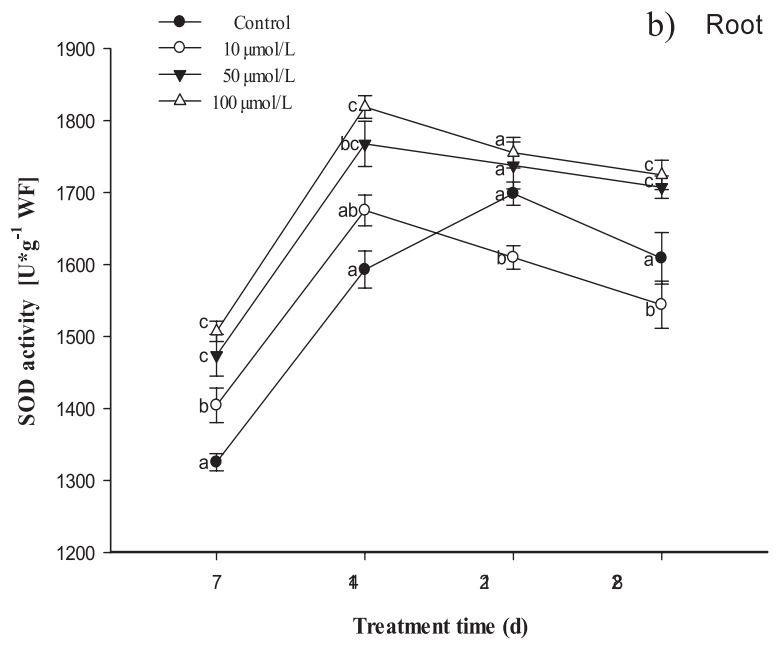



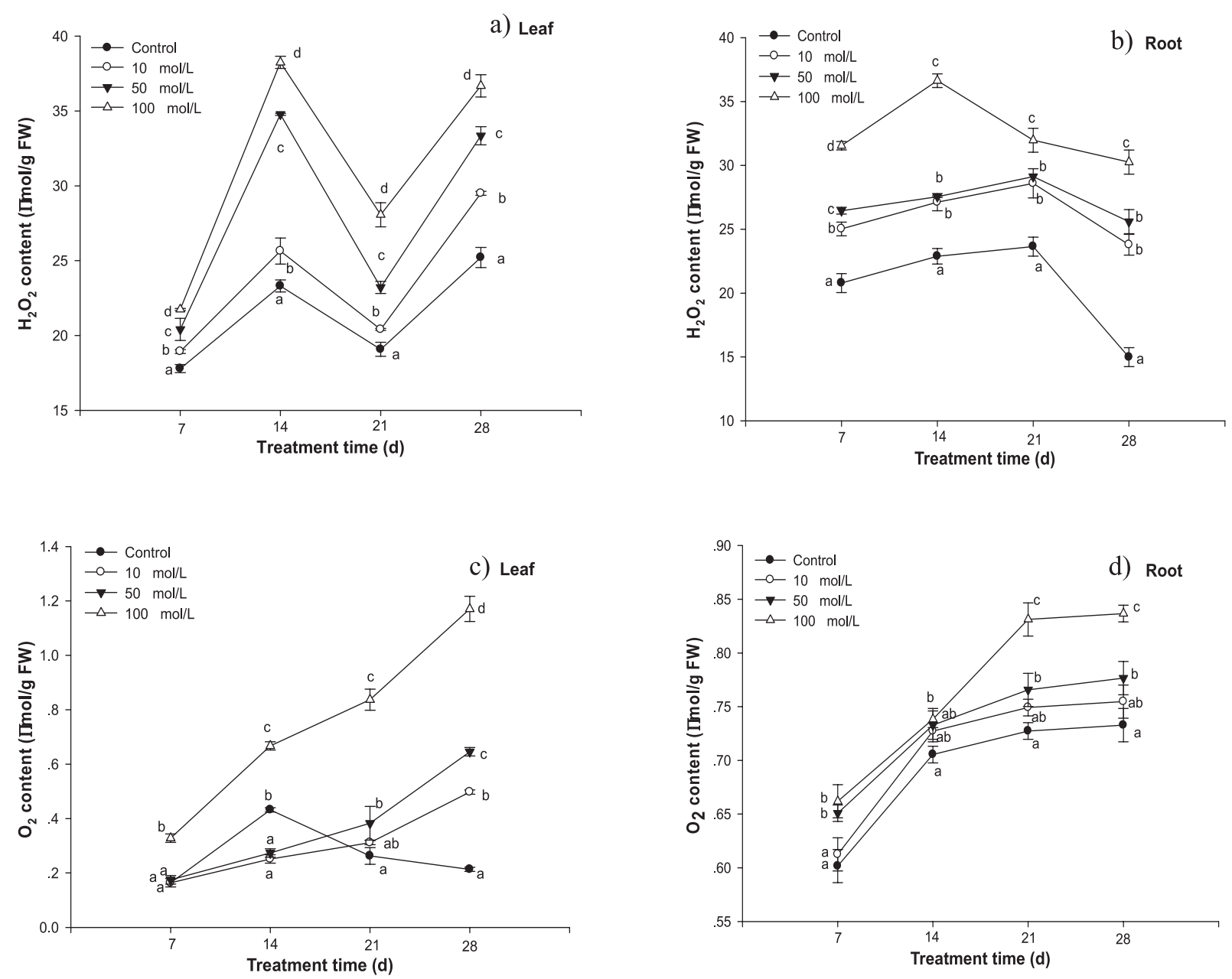

Fig. 3. Effect of different concentrations $\mathrm{Cd}$ on the activities of two reactive oxygen species in leaves and roots of $S$. matsudana stressed for 7, 14, 21 and $28 \mathrm{~d}$. Vertical bars denote $\mathrm{SE}, \mathrm{n}=5$. Values with different letters differ significantly from each other $(\mathrm{P}<0.05, \mathrm{t}$-test).

[24-26]. The $\mathrm{Cu}, \mathrm{Fe}, \mathrm{Mn}$, and $\mathrm{Zn}$ are employed by organisms to perform a remarkable array of functions that are critical to life. They are indispensable elements of photosynthesis, which act as cofactors mediating diverse biochemical processes including $\mathrm{CO}_{2}$ fixation, the synthesis of chlorophyll, the uncoupling of electron transport, ROS detoxification, and signaling events that stimulate molecular, cellular, and systemic responses [27]. In plants, these metal ions are absorbed from the soil through the roots and subsequently export from xylem parenchyma cells into xylem vessels responsible for long-distance transport to the stem [28]. The results from this investigation explained that high $\mathrm{Cd}$ concentration restrains the accumulation of $\mathrm{Cu}, \mathrm{Mn}$, and $\mathrm{Zn}$. On the contrary, low $\mathrm{Cd}$ concentration was able to accelerate these elements' absorption. During the whole treatment, $\mathrm{Fe}$ was still inhibited by $\mathrm{Cd}$. Moreover, some works have reported that the accumulation of $\mathrm{Fe}$ decreased under $\mathrm{Cd}$ stress [16].

Cd always causes disorders in mineral nutrition, and reduction in photosynthesis and oxidative stress by inducing ROS production in plants [29-30]. Normally, over-accumulation of ROS such as $\mathrm{O}_{2}^{-}, \mathrm{H}_{2} \mathrm{O}_{2}$, hydroxyl radicals (HO-), and singlet oxygen $\left({ }^{1} \mathrm{O}_{2}\right)$ have a serious effect on normal metabolism by disrupting cellular macromolecules like degradation of proteins, crosslinks in DNA, and membrane fatty acid peroxidation [31]. The antioxidant enzymatic defense systems in plants are good at eliminating ROS and protecting plants against oxidative damage and indicating metal toxicity $[5,32]$. The antioxidant enzymatic defense systems consist of SOD, POD, and CAT, representing a defensive strategy that plants use against $\mathrm{Cd}$ stress. The results also illustrated that prolonged exposure to $\mathrm{Cd}$ increased activities of the antioxidative enzymes, such as SOD, POD, and CAT. However, CAT activity in leaves at $\mathrm{Cd}$ treatment decreased its activity as exposure time increased. These antioxidative defense enzymes of $S$. matsudana could resist the $\mathrm{Cd}$ stress. Moreover, the results also showed that the content of $\mathrm{O}_{2}^{-}$and $\mathrm{H}_{2} \mathrm{O}_{2}$ were restrained at low $\mathrm{Cd}$ concentrations. The activity of antioxidant enzymes and the ROS contents in S. matsudana can serve as useful biomarkers in ecotoxicological tests with $\mathrm{Cd}$.

The results obtained in this investigation can provide valuable information for understanding the tolerance and detoxification mechanisms to $\mathrm{Cd}$ in S. matsudana and other woody plants and for choosing $S$. matsudana as one of the phytoremediation species for Cd-polluted soils. 


\section{Conclusions}

Based on the information provided in this article, it is concluded that: S. matsudana can be considered an efficient phytoextraction plant as it has considerable ability to accumulate $\mathrm{Cd}(\mathrm{Cd}$ concentration in shoot exceeding $0.01 \%(\mathrm{w} / \mathrm{w}))$. Cd can decrease the uptake and accumulation of $\mathrm{Cu}, \mathrm{Fe}, \mathrm{Mn}$, and $\mathrm{Zn}$ in $S$. matsudana. $\mathrm{Cd}$ induces high activities of SOD in roots and shoots and POD, CAT in roots, indicating that antioxidant enzymes provided a better defensive mechanism against Cd-induced oxidative damage in $S$. matsudana. In the presence of $\mathrm{Cd}$, the contents of $\mathrm{O}_{2}{ }^{--}$and $\mathrm{H}_{2} \mathrm{O}_{2}$ of $\mathrm{S}$. matsudana increase. $\mathrm{O}_{2}-$ and $\mathrm{H}_{2} \mathrm{O}_{2}$ were important ROS, which causes damage to cellular plasma membrane lipids and other biomolecules.

\section{Acknowledgements}

This project was supported by the Natural Science Foundation of Tianjin, China (grant No. 17JCYBJC22500). The authors wish to express their appreciation to the reviewers for their comments and suggestions.

\section{Conflict of Interest}

The authors declare no conflict of interest.

\section{Reference}

1. ELOBEID M., GOBEL C., FEUSSNER I., POLLE A. Cadmium interferes with auxin physiology and lignification in poplar. J. Exp. Bot. 63, 1413, 2012.

2. ERMAKOV V.V, PETRUNINA N.S., TYUTIKOV S.F., DANILOVA V.N., KHUSHVAKHTOVA S.D., DEGTYAREV A.P., KRECHETOVA E.V. Concentrating metals by plants of the genus Salix and their importance for identification of $\mathrm{Cd}$ anomalies. Geochemistry International, 53, 951, 2015.

3. MARTÍNEZ-LÓPEZ S., MARTÍNEZ-SÁNCHEZ M.J., PÉREZ-SIRVENT C., BECH J., GÓMEZ MARTINEZ M.C., GARCÍA-FERNANDEZ A.J. Screening of wild plants for use in the phytoremediation of mining-influenced soils containing arsenic in semiarid environments. J. Soils Sediments 14, 794, 2014.

4. YANG J.X., LI X.L., HU Y.B., GAO L.M., YAO D.X. Enrichment Characteristics of heavy metal cadmium in woody plants system. Kem. Ind. 64, 283, 2015.

5. EKMEKCI Y., TANYOLAC D., AYHAN B. Effects of cadmium on antioxidant enzyme and photosynthetic activities in leaves of two maize cultivars. J. Plant Physiol. $165,600,2008$

6. ZOU J.H., WANG G., JI J., WANG J.Y., WU H.F., OU Y.J., LI B.B. Transcriptional, physiological and cytological analysis validated the roles of some key genes linked $\mathrm{Cd}$ stress in Salix matsudana Koidz. Environ. Experi. Bot. 134, 116, 2017.

7. IORI V., ZACCHINI M., PIETRINI F. Growth, physiological response and phytoremoval capability of two willow clones exposed to ibuprofen under hydroponic culture. J. Hazard. Mater 262, 796, 2013.

8. HERNÁNDEZ J.A., JIMÉNEZ A., MULLINEAUX P., SEVILLA F. Tolerance of pea (Pisum sativum L.) to longterm salt stress is associated with induction of antioxidant defenses. Plant Cell Environ. 23, 853-862, 2000.

9. DINAKAR C., ABHAYPRATAP V., YEARLA S.R., RAGHAVENDRA A.S., PADMASREE K. Importance of ROS and antioxidant system during the beneficial interactions of mitochondrial metabolism with photosynthetic carbon assimilation. Planta 231, 461, 2010.

10. JIA Y., TANG S.R., WANG R.G., JU X.H., DING Y.Z., TU S.X., SMITH D.L. Effects of elevated $\mathrm{CO}_{2}$ on growth, photosynthesis, elemental composition, antioxidant level, and phytochelatin concentration in Lolium mutiforum and Lolium perenne under Cd stress. J. Hazard. Mater. 180, 384, 2010.

11. JIN C.W., MAO Q.Q., LUO B.F., LIN X.Y., DU S.T. Mutation of mpk6 enhances cadmium tolerance in Arabidopsis plants by alleviating oxidative stress. Plant Soil 371, 387, 2013

12. DAT J.F., VANDENABEELE S., VRANOVA E., VAN M.M., INZE D., VANBREUSEGEM F. Dual action of the active oxygen species during plant stress responses. Cell Mol. Life Sci. 57, 779, 2000.

13. WU H.F., WANG J.Y., OU Y.J., JIANG W.S., LIU D.H., ZOU J.H. Characterisation of early responses to cadmium in roots of Salix matsudana Koidz [J]. Toxicol. Environ. Chem. 99, 913, 2017.

14. WU H.F., WANG J.Y., LI B.B., ZOU J.H. Salix matsudana Koidz tolerance mechanisms to cadmium: uptake and accumulation, subcellular distribution, and chemical forms [J]. Pol. J. of Environ. Stud. 25, 1739, 2016.

15. ZOU J.H., YUE J.Y., JIANG W.S., LIU D.H. Effects of cadmium stress on root tip cells and some physiological indexes in Allium cepa var. agrogarum L. Acta Biol. Cracov. Bot. 54, 129, 2012.

16. LUX A., MARTINKA M., VACULIK M., WHITE P.J. Root responses to cadmium in the rhizosphere: a review. J. Exp. Bot. 62, 21, 2011.

17. ZACCHINI M., PIETRINI F., MUGNOZZA G.S., IORI V., PIETROSANTI L., MASSACCI A. Metal tolerance, accumulation and translocation in poplar and willow clones treated with cadmium in hydroponics.Water Air Soil Poll. 197, 23, 2009

18. VONDRÁČKOVÁ S., TLUSTOŠ P., HEJCMAN M., SZÁKOVÁ J. Regulation of macro, micro, and toxic element uptake by Salix $\times$ smithiana using liming of heavily contaminated soils. J. Soils Sediments 17, 1279, 2017.

19. BAKER A.J.M., BROOKS R.R., BAKER N.A. Terrestrial higher plants which hyperaccumulate metallic elements - a review of their distribution, ecology and phytochemistry. ScienceOpen Inc., Boston, 81, 1989.

20. BAKER A.J.M., WHITING S.N. In search of the Holy Grail - a further step in understanding metal hyperaccumulation? New Phytol. 155, 1, 2002.

21. POLLARD A.J., POWELL K.D., HARPER F.A., SMITH J.A.C. The genetic basis of metal hyperaccumulation in plants. Crit. Rev. Plant Sci. 21, 539, 2002

22. BAKER A.J.M., MCGRATH S.P., REEVES R.D. SMITH J.A.C. Metal hyperaccumulator plants: a review of the ecology and physiology of a biological resource for phytoremediation of metal-polluted soils. In: Terry, N., Bañuelos, G.S. (Eds.), Phytoremediation of Contaminated 
Soil and Water. CRC Press Inc., Boca Raton, FL, USA, 857, 2000.

23. ZÁRUBOVÁ P., HEJCMAN M., VONDRÁČKOVÁ S., MRNKA L., SZÁKOVÁ J., TLUSTOŠ P. Distribution of $\mathrm{P}, \mathrm{K}, \mathrm{Ca}, \mathrm{Mg}, \mathrm{Cd}, \mathrm{Cu}, \mathrm{Fe}, \mathrm{Mn}, \mathrm{Pb}$ and $\mathrm{Zn}$ in wood and bark age classes of willows and poplars used for phytoextraction on soils contaminated by risk elements. Environ. Sci. Pollut. R. 22, 18801, 2015.

24. CLEMENS S. Molecular mechanisms of plant metal tolerance and homeostasis. Planta 212, 475, 2001.

25. CLEMENS S., PALMGREN M.G., KRÄMER U. A long way ahead: understanding and engineering plant metal accumulation.Trends Plant Sci. 7, 309, 2002.

26. SEBASTIANI L., SCEBBA F., TOGNETTI R. Heavy metal accumulation and growth responses in poplar clones Eridano (Populus deltoides $\times$ maximowiczii) and I-214 $(P . \times$ euramericana $)$ exposed to industrial waste. Environ. Exp. Bot. 52, 79, 2004.

27. ASTOLFI S., ORTOLANIA M.R., CATARCIONEA G., PAOLACCIA A.R., CESCOB S., PINTON R., CIAFFI M. Cadmium exposure affects iron acquisition in barley (Hordeum vulgare) seedlings. Physiol. Plantarum 152, 646, 2014.

28. MIKKELSEN M.D., PEDAS P., SCHILLER M., VINCZE E., MILLS.R.F., BORG S., MOLLER A., SCHJOERRING
J.K., WILLIAMS L.E., BAEKGAARD L., HOLM P.B., PALMGREN M.G. Barley HvHMA1 is a heavy metal pump involved in mobilizing organellar $\mathrm{Zn}$ and $\mathrm{Cu}$ and plays a role in metal loading into grains. Plos One 7, e49027, 2012.

29. DUBEY R.S. Metal toxicity, oxidative stress and antioxidative defense system in plants. In: Gupta SD (ed) Reactive oxygen species and antioxidants in higher plants. Science Publishers, CRC Press,Taylor and Francis Group, USA, 177, 2010.

30. GALLEGO S.M., PENA L.B., BARCIA R.A., AZPILICUETA C.E., IANNONE M.F., ROSALES E.P., ZAWOZNIK M.S., GROPPA M.D., BENAVIDES M.P. Unravelling cadmium toxicity and tolerance in plants: insight into regulatory mechanisms. Environ. Exp. Bot. 83, 33, 2012.

31. SHARMA P., JHA A.B., DUBEY R.S., PESSARAKLI M. Reactive oxygen species, oxidative damage, and antioxidative defense mechanism in plants under stressful conditions. J Bot. 2012, 217037, 2012.

32. LI D.D., ZHOU D.M., WANG P., WENG N.Y., ZHU X.D. Subcellular $\mathrm{Cd}$ distribution and its correlation with antioxidant enzymatic activities in wheat (Triticum aestivum) roots. Ecotox. Environ. Safe 74, 874, 2011. 
